\title{
Voltammetric Generation and Kinetic Stability of Nitro Anion Radical from Nitrofurazone in Ionic Liquids
}

\author{
Luisa D. Chiavassa, ${ }^{a}$ Fernanda F. Camilo ${ }^{b}$ and Mauro A. La Scalea ${ }^{(*, c}$ \\ ${ }^{a}$ Grupo de Eletroquímica Interfacial, Centro de Química Estrutural, \\ Faculdade de Ciências da Universidade de Lisboa, 1749-016 Lisboa, Portugal \\ ${ }^{b}$ Laboratório de Materiais Híbridos, Departamento de Química, \\ Instituto de Ciências Ambientais Químicas e Farmacêuticas, \\ Universidade Federal de São Paulo, 09913-030 Diadema-SP, Brazil \\ ${ }^{c}$ Laboratório de Eletroquímica e Eletroanálise, Departamento de Química, \\ Instituto de Ciências Ambientais Químicas e Farmacêuticas, \\ Universidade Federal de São Paulo, 09972-270 Diadema-SP, Brazil
}

\begin{abstract}
The nitrofurazone (NF) electrochemical reduction has been studied by cyclic voltammetry $(\mathrm{CV})$ and square wave voltammetry (SWV) in non-aqueous medium using three different ionic liquids (IL): $\mathrm{BMImTf}_{2} \mathrm{~N}, \mathrm{BMImBF}_{4}$ and $\mathrm{BMMImTf}_{2} \mathrm{~N}$, having a carbon fiber microelectrode as working electrode. In all of them, two reversible cathodic peaks were recorded for NF. Under higher frequency values, only one reversible cathodic peak was registered. The systems reversibility could also be observed by $\mathrm{CV}$, since a reversible redox couple was registered for this reduction. The systems reversibility with product and reagent adsorptions on the electrode surface was confirmed and the electrons number involved in this reduction indicated the nitro-anion radical formation followed by its respective dianion. For the first reduction, the EC mechanism (an electrochemical step followed by a chemical one) was considered for the systems in aprotic medium, in which there was a probable second-order chemical reaction after the charge transfer process, being the kinetic constants calculated following the Olmstead and Nicholson model.
\end{abstract}

Keywords: nitrofurazone, nitro-anion radical, ionic liquids, voltammetry, EC mechanism

\section{Introduction}

Nitrocompounds belong to a class of organic compounds widely used as solvents, pesticides, dyes, explosives and drugs. ${ }^{1,2}$ The therapeutic use of nitrocompounds as drugs deserves to be highlighted due to their wide range of biological actions, being classified as antibacterial, antiprotozoal and anticancer agents. ${ }^{3}$ In general, these biological activities are a result of their interaction with the biological targets from the nitro group reduction by nonspecific nitroreductases, generating free radicals that cause toxic oxidative stress in bacteria and parasites. ${ }^{3-5}$ The nitro-heterocyclic compound, nitrofurazone (Figure 1), is commonly used as a prototype for the new drugs development due to its antiprotozoal activity, ${ }^{4,6,7}$ especially for Chagas disease, which is considered one of the most

*e-mail: mauro.scalea@unifesp.br serious health problems in the Latin America for being an endemic disease..$^{7,8}$<smiles>NC(=O)N/N=C/c1ccc([N+](=O)[O-])o1</smiles>

Figure 1. Nitrofurazone (NF).

The nitro-heterocycles have a complex and well-known reduction mechanism in which the formation of the nitroanion radical $\left(\mathrm{R}-\mathrm{NO}_{2}{ }^{-}\right)$and the hydroxylamine derivative $(\mathrm{R}-\mathrm{NHOH})$ are accepted as the main species responsible for the compounds cytotoxic action. ${ }^{9,10}$ The nitro group is known to be capable of receiving up to six electrons in its complete reduction to amine derivative, ${ }^{11-14}$ as shown in Scheme 1. Proton and electron transfers are involved in several steps of the nitro group reduction, which clearly 


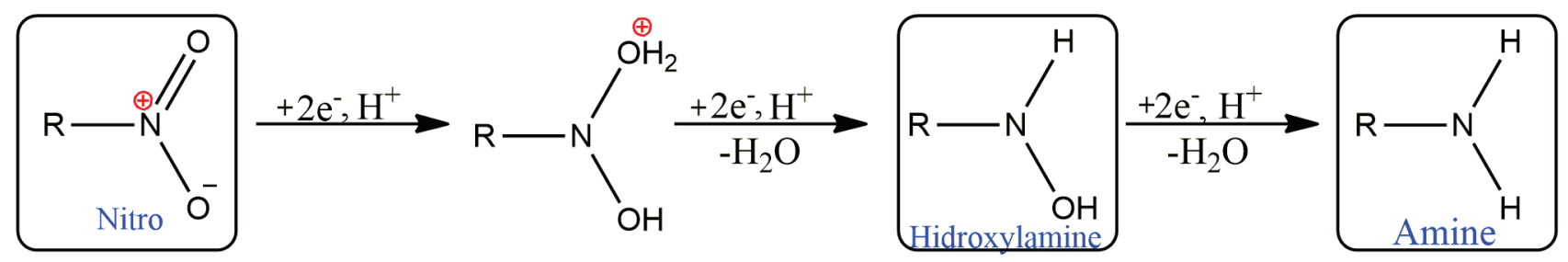

Scheme 1. Complete reduction mechanism of the nitro group.

suggests the use of electrochemical techniques as excellent tools to study this kind of drugs. In addition, nitroaromatic compounds are ideal candidates for electrochemical detection due to their easily reducible nitro groups which originates distinct current response even in low concentrations..$^{15-19}$ In this context, several studies ${ }^{11,15,16}$ on the voltammetric behavior of nitro-heterocycles have been performed in order to comprehend the species which have biological performance to specific targets.

The voltammetric reduction mechanism of nitroheterocycles can be significantly affected by the medium in which the reaction is carried out. Classically, in acidic medium, two voltammetric waves are registered, being the hydroxylamine derivative formation detected at less negative potential values followed by the second reduction process due to the amine derivative formation. ${ }^{11-14}$ Distinctly, in alkaline aqueous media or aprotic/non-aqueous media, the nitro-anion radical generation is facilitated in function of low concentration or absence of protons in solution. In this case, the reversible redox process corresponding to the $\mathrm{R}-\mathrm{NO}_{2} / \mathrm{R}-\mathrm{NO}_{2}{ }^{-}$couple, involving one electron, is registered before the hydroxylamine derivative formation. ${ }^{11-14}$ Additionally, an irreversible chemical reaction can occur after the reversible charge transfer process, characterizing an EC mechanism (an electrochemical step followed by a chemical one), in which the $\mathrm{R}_{-} \mathrm{NO}_{2}^{-}$decay is promoted by means of a disproportionation reaction (protic/alkaline aqueous media) or dimerization reaction (aprotic/mixed solvents or non-aqueous media), determining the kinetic stability of nitro-anion radical electrochemically generated. ${ }^{11-14}$

Among the non-aqueous media sometimes required in reason of the substrates low solubility in traditional aqueous electrolytes, the ionic liquids (IL) stand out due to their good dissolution capacity, wide electrochemical range and intrinsic conductivity. ${ }^{20,21}$ In addition, electrochemical reaction mechanism occurring in IL can be entirely changed compared to that seen in conventional solvents, ${ }^{22}$ since the mass transport properties and stability of the generated species are modified in this ionic medium. Therefore, the evaluation of nitrocompounds in ionic liquids can be useful. In this sense, several works ${ }^{23-27}$ can be quoted as examples by the IL application versatility in electrochemistry of nitrocompounds.
Zhang et al. ${ }^{23}$ proposed electrochemical reduction mechanism of nitrobenzene in 1-butyl3-methylimidazolium acetate (BMImAc). The results showed that the electrochemical process could be controlled by diffusion and that the main product formed at $-1.45 \mathrm{~V}$ was azobenzene. A probable reaction mechanism in ionic liquid was proposed, following the formation sequence nitrobenzene $\rightarrow$ nitrosobenzene $\rightarrow$ azobenzene $\rightarrow$ aniline.

Studies ${ }^{24,25}$ involving the nitrobenzene reduction and 4-nitrophenol in 1-butyl-2,3-dimethylimidazole bis(trifluoromethanesulfonyl)imide $\left(\mathrm{BMMImTf}_{2} \mathrm{~N}\right)$ were reported using a gold microelectrode. The reduction mechanisms reported are similar to those in aprotic organic solvents, with differences in voltammetric results mainly due to the viscosities of the ionic liquids. Silvester and co-workers ${ }^{26,27}$ developed mechanistic studies involving the 2,4,6-trinitrotoluene (TNT) and 2,4-dinitrotoluene (DNT) reductions in IL by cyclic voltammetry, in which two and three reduction peaks were observed corresponding, respectively, to the two and three nitro groups on the aromatic ring. The authors propose that a chemical step occurs after the charge transfer process registered by the first reduction peak, characterizing the EC mechanism for both cases when high concentrations of these compounds are used. Based on the TNT and DNT reductions described above, using a glassy carbon electrode, Zeng and co-workers ${ }^{28}$ evaluated the reaction mechanisms for the nitro group as a function of the cation and anion composition of ionic liquids and their consequent variation in the physicochemical properties such as viscosity and conductivity as well as solvation forces involving hydrogenbonding donation ability.

In this context, most studies about the reduction mechanism and electrochemical kinetic of nitroheterocyclic compounds reaction are mainly performed in aqueous medium as well as conventional non-aqueous. Therefore, among the studies that include non-aqueous medium, there are a few ${ }^{25-27}$ that use ionic liquids as an alternative, especially when square wave voltammetry is chosen as electrochemical investigative technique. Considering that, the present study carried out by square wave and cyclic voltammetries by using three different IL (Figure 2) brings a description of the nitrofurazone 
electrochemical reduction in order to understand both, the nitro-anion radical generation process and its kinetic stability in these media.<smiles>CCCCn1cc[n+](C)c1</smiles>

(a)<smiles>CCCCn1cc[n+](C)c1</smiles>

(b)
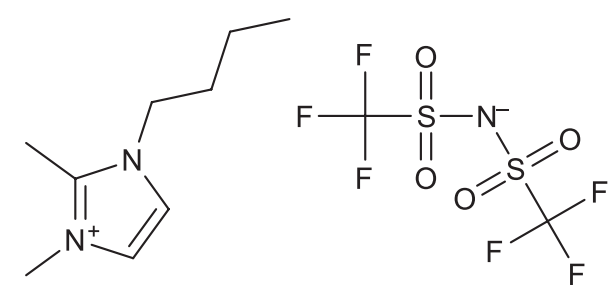

(c)

Figure 2. Ionic liquids: $\mathrm{BMImTf}_{2} \mathrm{~N}(\mathrm{a}), \mathrm{BMImBF}_{4}$ (b) and $\mathrm{BMMImTf} \mathrm{II}_{2} \mathrm{~N}$ (c).

\section{Experimental}

Instrumentation

All the electrochemical measurements were performed with a pontenciostat/galvanostat Autolab PGSTAT302, Eco-Chimie, using an electrochemical cell with a three-electrode system. Carbon fiber microelectrode was used as working electrode, $\mathrm{Pt}$ as auxiliary and a silver wire (Ag) as pseudo-reference electrode, whose calibration was done in a $1.5 \mathrm{mmol} \mathrm{L}{ }^{-1}$ ferrocene solution in acetonitrile with oxidation peak at $0.625 \mathrm{~V}$ with a $0.225 \mathrm{~V}$ lagging to the reference electrode $\mathrm{Ag} / \mathrm{AgCl}\left(3.0 \mathrm{~mol} \mathrm{~L}^{-1} \mathrm{KCl}\right)$ in the same condition. ${ }^{29}$ The homemade carbon fiber microelectrode was manually polished with alumina suspension on metallographic velvet (Arotec). Its effective area $\left(3.48 \mu \mathrm{m}^{2}\right)$ was determined following methodology already reported ${ }^{30}$ by cyclic voltammetric data obtained for $0.010 \mathrm{~mol} \mathrm{~L}^{-1}$ of $\mathrm{K}_{3} \mathrm{Fe}(\mathrm{CN})_{6}$ in $0.5 \mathrm{~mol} \mathrm{~L}^{-1} \mathrm{KCl}$ solution, being the diffusion coefficient $7.76 \times 10^{-6} \mathrm{~cm}^{2} \mathrm{~s}^{-1}$. 31 The electrochemical behavior of the nitrofurazone was studied in IL by cyclic voltammetry (CV) and square wave voltammetry (SWV).

Reagents, solutions and ionic liquids

The stock solutions of $10 \mathrm{mmol} \mathrm{L}{ }^{-1}$ of nitrofurazone (Avocado Company, Morecambe, United Kingdom) were prepared through direct dissolution in the ionic liquids. The solution was stocked in amber flasks, kept under refrigeration $\left(4{ }^{\circ} \mathrm{C}\right)$ and light protected. It was used analytical-grade reagents and ultrapure water from Millipore system Milli-Q from Merck (Darmstadt, Germany) The ionic liquids $\mathrm{BMImTf}_{2} \mathrm{~N}, \mathrm{BMImBF}_{4}$ and $\mathrm{BMMImTf}_{2} \mathrm{~N}$ were synthesized following previous procedure ${ }^{32}$ and characterized by nuclear magnetic resonance (NMR) spectroscopy (Figures S1-S3, Supplementary Information (SI) section). The voltammetric blank of all ionic liquids was performed in order to ensure that there were no obvious voltammetric events within the available potential range from 0.5 to $-1.5 \mathrm{~V}$.

Peak current ratio calculations

The calculated ratio between anodic and cathodic peak currents obtained by cyclic voltammetry registered in IL followed the Olmstead et al..$^{33}$ methodology:

$\frac{\mathrm{Ipa}}{\mathrm{Ipa}}=\frac{(\mathrm{Ipa})_{0}}{(\mathrm{Ipc})_{0}}+\left[\frac{(\mathrm{Isp})_{0}}{(\mathrm{Ipc})_{0}}\right]^{2} \beta+\frac{(\mathrm{Isp})_{0}}{(\mathrm{Ipc})_{0}} \gamma+\xi$

Being $\left(\mathrm{I}_{\mathrm{pa}}\right)_{0}$ and $\left(\mathrm{I}_{\mathrm{pc}}\right)_{0}=$ anodic and cathodic peak currents, respectively, $\left(\mathrm{I}_{\mathrm{sp}}\right)_{0}=$ current measured in the inversion potential, $\beta=0.9678, \gamma=-0.5370, \xi=0.3337$.

\section{Kinetic parameter calculations}

For the kinetic constants calculation the OlmsteadNicholson model ${ }^{33}$ was adopted, considering that a dimer is formed after the electron transfer process at a fully spherical electrode, plotting a working curve with the fit equation, being the correlation coefficient $(R)=0.99998$, described below:

$\mathrm{y}=0.60007+0.14894 \mathrm{e}^{(-\mathrm{x} / 0.41669)}+0.25042 \mathrm{e}^{(-\mathrm{x} / 1.70667)}$

being $\mathrm{y}=\omega$ and $\mathrm{x}=\mathrm{I}_{\mathrm{pa}} / \mathrm{I}_{\mathrm{pc}}$.

Taking into account the sphericity character for the microelectrode, the $\omega$ kinetic parameters were determined through interpolation the $\mathrm{I}_{\mathrm{pa}} / \mathrm{I}_{\mathrm{pc}}$ values obtained from experimental voltammograms. The $\omega$ parameter incorporates the effects of the rate constant $\left(\mathrm{k}_{2}\right)$, drug concentration $(\mathrm{C})$ and scan rate. 
The plot obtained between $\omega$ and $\tau$ is a linear fit correlation, following the equation below.

$\omega=\mathrm{k}_{2} \mathrm{C} \tau$

Considering $\mathrm{k}_{2}$ = rate constant value for the secondorder reaction for the nitro-anion radical decay $\left(\mathrm{L} \mathrm{mol}^{-1} \mathrm{~s}^{-1}\right)$, $\mathrm{C}=$ nitrofurazone $(\mathrm{NF})$ concentration $\left(\mathrm{mol} \mathrm{L} \mathrm{L}^{-1}\right)$ and $\tau=\left(E_{1 / 2}-E s\right) / v$, being $E_{1 / 2}$ correspondent to the half-wave potential, Es corresponds to the initial potential of the reverse scan in $\mathrm{CV}$, and $\mathrm{v}$ is the scan rate $\left(\mathrm{V} \mathrm{s}^{-1}\right)$. From the calculated $\mathrm{k}_{2}$ by the slope, the nitro-anion radical stability can be estimated by the half-life $\left(\mathrm{t}_{1 / 2}\right)$ equation, assuming $\left[\mathrm{R}-\mathrm{NO}_{2}{ }^{--}\right]$as drug concentration.

$\mathrm{t}_{1 / 2}=\frac{1}{\mathrm{k}_{2}\left[\mathrm{R}-\mathrm{NO}_{2}^{--}\right]}$

\section{Results and Discussion}

Voltammetric behavior of NF reduction in ionic liquids

The IL used in this work were selected according to their electrochemical and physicochemical characteristics (Table S1, SI section), depending on their

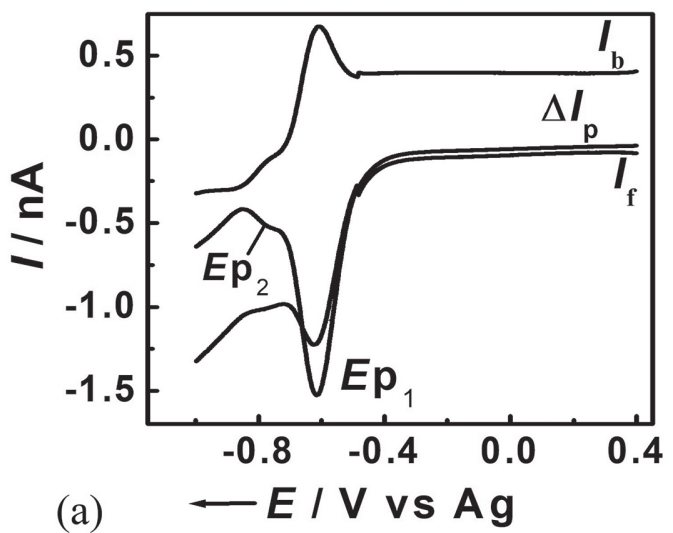

constituents (cations and anions). ${ }^{32}$ The ionic liquids containing 1-alkyl-3-methylimidazolium $\left(\mathrm{BMIm}^{+}\right)$and 1,2-dimethylimidazolium $\left(\mathrm{BMMIm}^{+}\right)$species were chosen in view of the fact that these cations confer high electrochemical stability and lower viscosity for the IL. ${ }^{26}$ The difference between $\mathrm{BMIm}^{+}$and $\mathrm{BMMIm}^{+}$is that the former has an acidic hydrogen in the $\mathrm{C}-2$, bringing a differential that can be determinant for the proposed study. ${ }^{26,28,34} \mathrm{Tf}_{2} \mathrm{~N}^{-}$ and $\mathrm{BF}_{4}^{-}$based on ionic liquids were selected since both display excellent electrochemical stability, even having different viscosities. ${ }^{26} \mathrm{Tf}_{2} \mathrm{~N}^{-}$has delocalized charge, being larger than $\mathrm{BF}_{4}^{-}$anion, influencing the ion-pairing in these ionic liquids. It is known that ion-pairing interactions affect the stability of the anion-radical. ${ }^{26,28}$

The $10 \mathrm{mmol} \mathrm{L}^{-1} \mathrm{NF}$ reduction was studied with SWV, using frequency $(f)=10 \mathrm{~Hz}$; amplitude $(\mathrm{a})=50.0 \mathrm{mV}$ and sweeping increase $(\Delta \mathrm{Es})=2.0 \mathrm{mV}$, in the three different IL indicated above (Figure 3 ). All the voltammetric records were obtained by using a carbon fiber microelectrode considered as the best option for the electrochemical measurements, since the volumes obtained by the IL syntheses were significantly small $(2 \mathrm{~mL}$ was the volume in electrochemical cell) in addition to the advantage of being a homemade microelectrode. Furthermore, microelectrodes have greater mass transport due to the

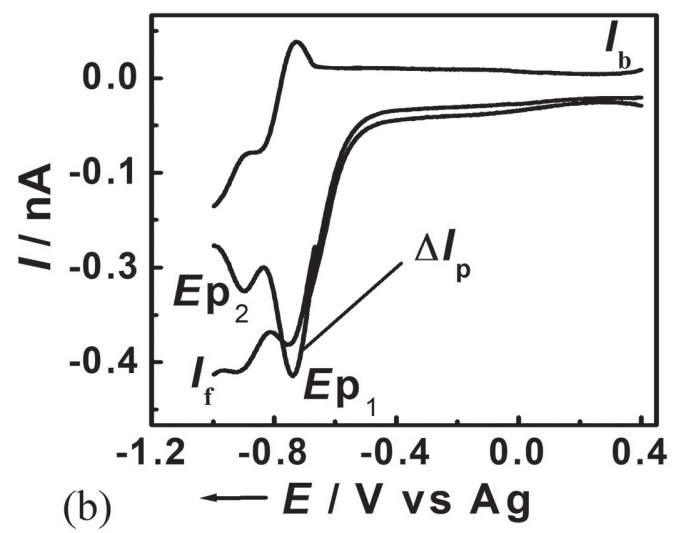

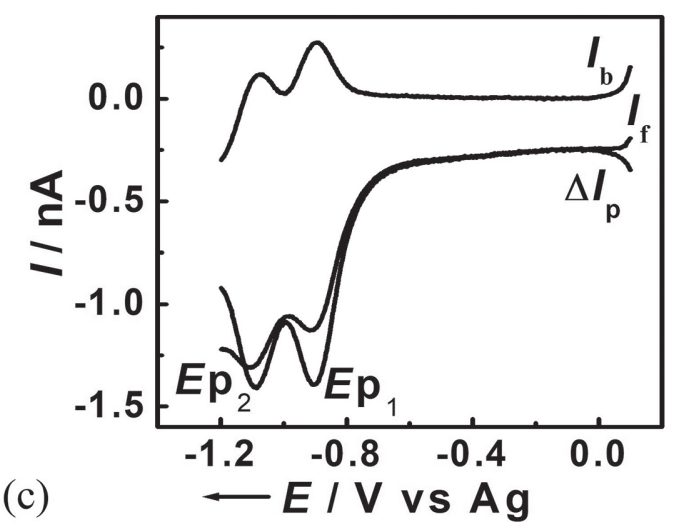

Figure 3. NF square wave voltammograms in $\mathrm{BMImBF}_{4}(\mathrm{a}), \mathrm{BMImTf}_{2} \mathrm{~N}(\mathrm{~b})$ and $\mathrm{BMMImTf}_{2} \mathrm{~N}(\mathrm{c}) 10.0 \mathrm{mmol} \mathrm{L}-1(f=10 \mathrm{~Hz} ; \Delta \mathrm{Es}=2.0 \mathrm{mV}$ and a $=50.0 \mathrm{mV})$. 
spherical shape of the diffusion layer, facilitating the study of fast electrode reactions and the detection of reaction intermediates which lifetime is very short, such as the formation of radicals. Additionally, the currents measured with microelectrodes are small and do not significantly change the concentration of the electrolyzed species in the solution, so the responses are not so sensitive to errors due to the ohmic drop, therefore, the microelectrodes could be used in solutions with large resistance, such as IL, in the absence of supporting electrolytes. ${ }^{14}$ The voltammograms presented two cathodic peaks $\left(\mathrm{E}_{\mathrm{p} 1}\right.$ and $\left.\mathrm{E}_{\mathrm{p} 2}\right)$ at -0.623 and $-0.783 \mathrm{~V},-0.742$ and $-0.901 \mathrm{~V},-0.902$ and $-1.089 \mathrm{~V}$ for $\mathrm{BMImBF}_{4}, \mathrm{BMImTf}_{2} \mathrm{~N}$ and $\mathrm{BMMImTf}_{2} \mathrm{~N}$, respectively. From the current-components evaluation, it was possible to observe the existence of a reversible system, since the net currents $\left(\Delta \mathrm{I}_{\mathrm{p}}\right)$ were made up of direct $\left(\mathrm{I}_{\mathrm{f}}\right)$ and reverse $\left(\mathrm{I}_{\mathrm{b}}\right)$ components, as well as previously registered in aqueous media. ${ }^{14}$ Thus, for all IL shown in Figure 3, the peaks represented in the voltammograms as $\mathrm{E}_{\mathrm{p} 1}$ and $\mathrm{E}_{\mathrm{p} 2}$ had the current components $\mathrm{I}_{\mathrm{f}}$ and $\mathrm{I}_{\mathrm{b}}$ from the $\Delta \mathrm{I}_{\mathrm{p}}$ decomposition, demonstrating the existence of two reversible systems. ${ }^{35-37}$

In order to obtain information related to the electrode processes, the previous procedure tested in aqueous media was followed, ${ }^{14}$ being the frequency variation study also performed in IL. The frequency varied from 10 to $250 \mathrm{~Hz}$, in

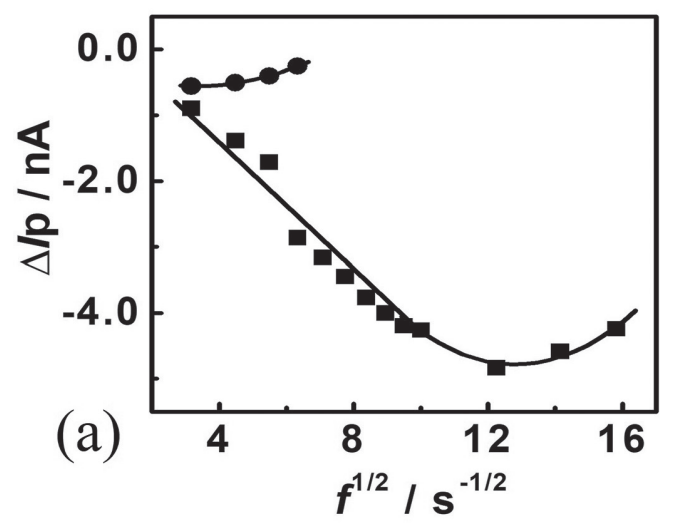

which $\mathrm{a}=50.0 \mathrm{mV}$ and $\Delta \mathrm{Es}=2.0 \mathrm{mV}$ were maintained. The $\mathrm{E}_{\mathrm{p} 2}$ was observed throughout the frequency range studied in $\mathrm{BMMImTf}_{2} \mathrm{~N}$. However, in $\mathrm{BMImBF}_{4}$ and $\mathrm{BMImTf}_{2} \mathrm{~N}$, $\mathrm{E}_{\mathrm{p} 2}$ was registered only at frequencies lower than 50 and $70 \mathrm{~Hz}$, respectively (results not shown).

According to literature, ${ }^{35,36}$ the reversibility of the system could be verified by the linear relationship between $\Delta \mathrm{I}_{\mathrm{p}}$ and $f^{1 / 2}$, which can be seen in Figure 4. For the NF reduction in the three IL, the linear relationship was found in $10 \mathrm{~Hz} \leq f \leq 100 \mathrm{~Hz}$ range. For $f>100 \mathrm{~Hz}$, it can be observed in Figure 4 that the behavior was changed in all cases. It is known that the greater the reversibility of the reaction, the higher the reverse current contribution implying an increase of $\Delta \mathrm{I}_{\mathrm{p}}$ intensity, since the peak current value is the result of the difference between $\mathrm{I}_{\mathrm{f}}$ and $\mathrm{I}_{\mathrm{b}} \cdot{ }^{35,36}$ In this case, the $\Delta \mathrm{I}_{\mathrm{p}}$ decrease at higher frequency values suggests a lower $\mathrm{I}_{\mathrm{b}}$ contribution with consequent loss of reversibility. Possibly, in these specific reduction process, the systems were apparently reversible at lower and quasireversible to higher frequencies. ${ }^{35,36}$ Similar behavior has also been recorded for the NF in aqueous media. ${ }^{14}$

The opposite occurred for $\Delta \mathrm{I}_{\mathrm{p} 2}$, in which there was practically no net current increase with the frequency variation, indicating that the system reversibility tends to decrease with the increased $f$, reason why at frequencies

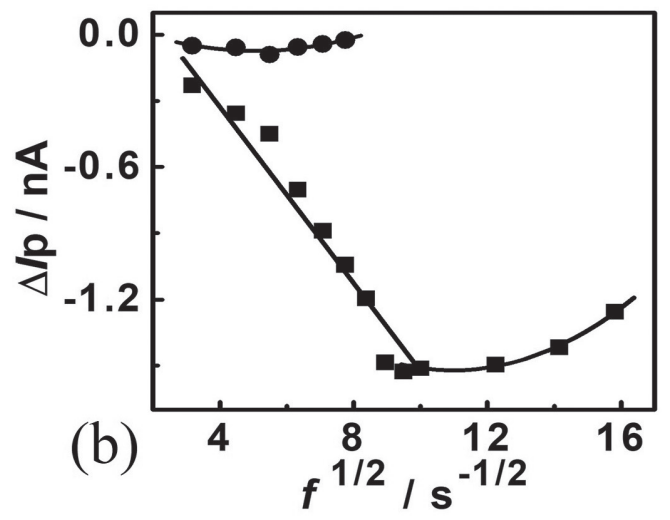

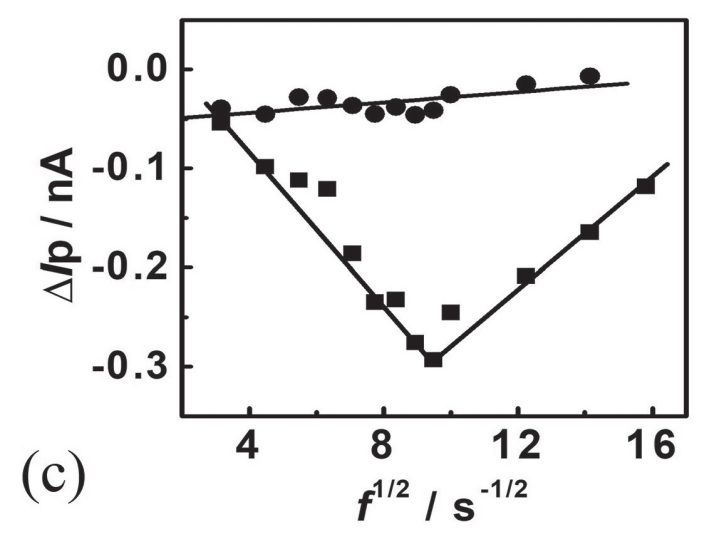

Figure 4. Plots of $\Delta \mathrm{I}_{\mathrm{p} 1}(\boldsymbol{\bullet})$ and $\Delta \mathrm{I}_{\mathrm{p} 2}(\bullet) v s$. $f^{1 / 2}$ for $\mathrm{NF}$ in $\mathrm{BMImBF}_{4}(\mathrm{a}), \mathrm{BMImTf}_{2} \mathrm{~N}$ (b) and $\mathrm{BMMImTf}_{2} \mathrm{~N}(\mathrm{c})$. 
higher than $50 \mathrm{~Hz}$ in $\mathrm{BMImBF}_{4}$ and $70 \mathrm{~Hz}$ in $\mathrm{BMImTf}_{2} \mathrm{~N}$ there was no second reduction process record since the charge transfer process occurred more slowly than the potential scan rate. It is worth recalling that the scan rate for SWV analysis is given as function of the potential sweep increment and the potential pulses application frequency $(f \times \Delta \mathrm{Es}){ }^{34}$ Therefore, as the potential values increment remained constant during the analyses, the scan rate increased according to the frequency increase. In this sense, the charge transfer process may be associated with the viscosity of each IL, since the diffusion coefficients decreased as the IL viscosity increased and the charge transfer occurred more slowly.

Figure 5 shows the relationship between peak potential values $\left(\mathrm{E}_{\mathrm{p} 1}\right.$ and $\left.\mathrm{E}_{\mathrm{p} 2}\right)$ and the $\log f$. The potential values for both peaks were practically kept constant with the frequency variation correspondent to the range in which the NF reduction was considered reversible for all IL studied (Figure 4, $f \leq 100 \mathrm{~Hz}$ ), suggesting that reagents and products were adsorbed on the electrode surface..$^{35}$ According to the SWV theoretical model ${ }^{35,36}$ for reversible systems, it is possible to calculate the kinetic rate constants of the reaction $\left(\mathrm{k}_{\mathrm{r}}\right)$ for each system applying the equation $\mathrm{I}_{\mathrm{p}}=\mathrm{k}_{\mathrm{r}} f^{1 / 2}$. Regarding the $\mathrm{k}_{\mathrm{r}}$ values and considering the ratio of $\log \mathrm{k}_{\mathrm{r}} / 2 f$ as determinant to clarify the mass transport

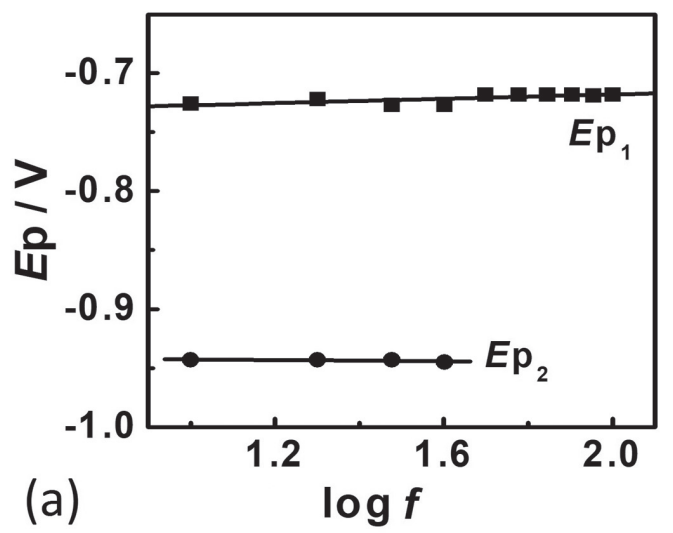

process in the system, this ratio was calculated for the frequency range in all cases. For $f=10 \mathrm{~Hz}$, the values of $0.477,0.507$ and 0.538 were estimated in $\mathrm{BMImBF}_{4}$, $\mathrm{BMImTF}_{2} \mathrm{~N}$ and $\mathrm{BMMImTF}_{2} \mathrm{~N}$, respectively, being, in this way, approximated to the established ratio value of 0.5 for reagent and product adsorption on the electrode surface. ${ }^{35,36}$ However, the increased frequency provoked a significant decrease in these values, indicating loss of product and reagent adsorptions, which could be inferred that the system was not completely controlled by adsorption but by diffusional process at higher frequencies. In this sense, the the equation $E_{p / 2}=97 / \mathrm{n} \mathrm{mV}$, being $E_{p / 2}$ the width at halfheight peak and $n$ the electrons number in the processes, was applied for the lowest frequency value $(10 \mathrm{~Hz})$ for which the SWV theoretical model ${ }^{35,36}$ was completely fitted. Based on this behavior, the electrons number for both reduction processes correspondent to $\mathrm{E}_{\mathrm{p} 1}$ and $\mathrm{E}_{\mathrm{p} 2}$ were estimated (Table S2, SI section), being the values found between 0.85 and 0.88 for $\mathrm{E}_{\mathrm{p} 1}$ and between 0.93 and 1.20 for $\mathrm{E}_{\mathrm{p} 2}$.

Considering previous results, ${ }^{12-14}$ the reversible system observed at less negative potentials $\left(\mathrm{E}_{\mathrm{p} 1}\right)$ was associated to the nitro-anion radical generation from $\mathrm{NF}$ in the three IL studied, according to the reaction in Scheme 2. Additionally, the dianion formation has been identified as the correspondent product obtained at $\mathrm{E}_{\mathrm{p} 2}$. Literature works ${ }^{28,38}$

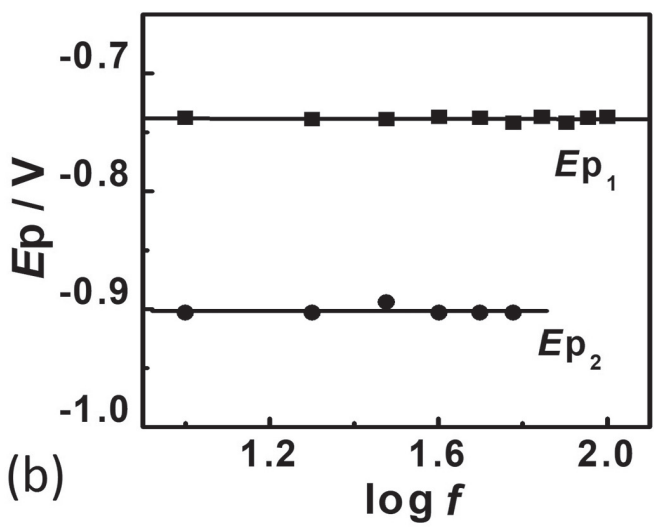

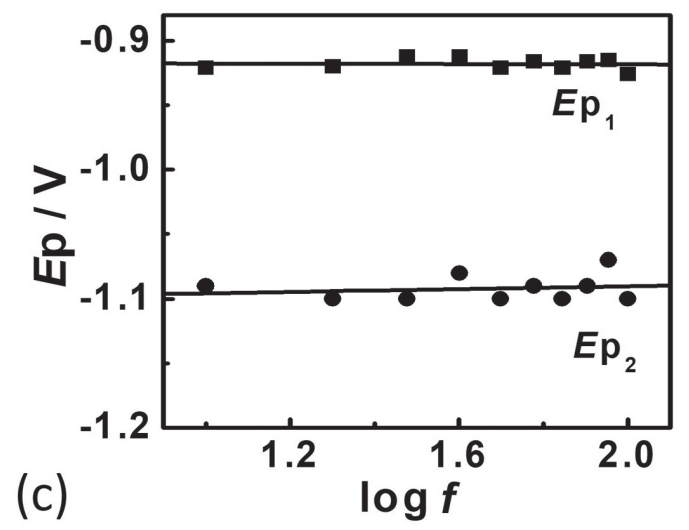

Figure 5. Plots of $\mathrm{E}_{\mathrm{p} 1}(\boldsymbol{\bullet})$ and $\mathrm{E}_{\mathrm{p} 2}(\bullet)$ vs. $\log f$ for $\mathrm{NF}_{\text {in }} \mathrm{BMImBF}_{4}(\mathrm{a}), \mathrm{BMImTf}_{2} \mathrm{~N}(\mathrm{~b})$ and $\mathrm{BMMImTf}_{2} \mathrm{~N}(\mathrm{c})$. 


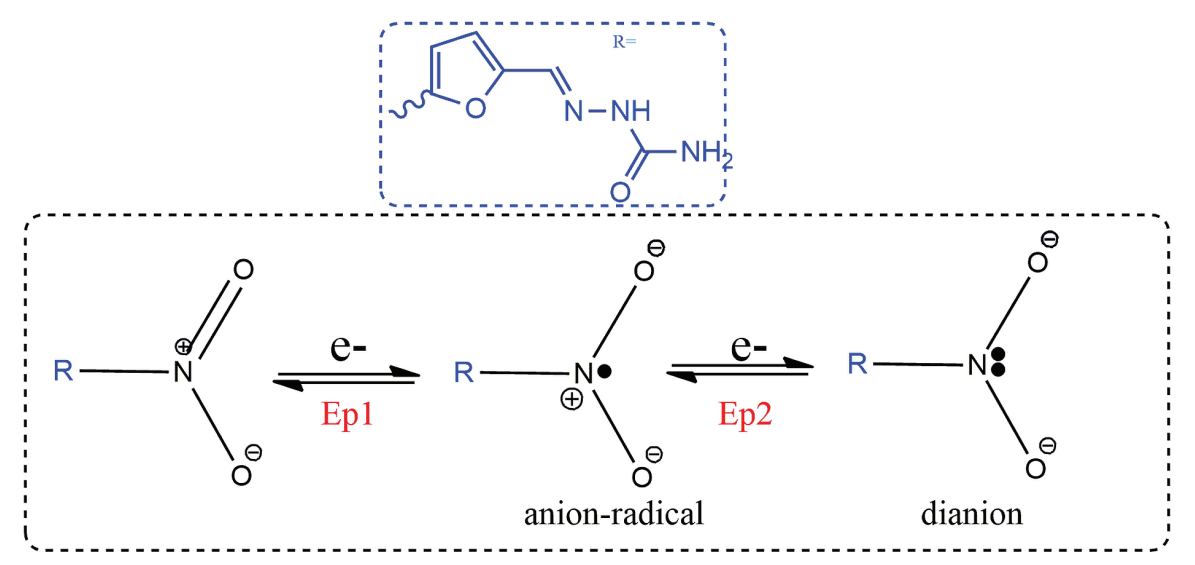

Scheme 2. Reduction mechanism for the nitro-anion radical generation followed by the corresponding dianion formed.

have shown that the nitrocompounds voltammetric reduction in IL presents the possibility of the dianion formation after the nitro-anion radical generation. This formation might be accompanied by a certain instability, since the dianion is a strong Lewis base capable of removing protons from species normally non-donors under normal conditions, as it occurs with $\mathrm{BMIm}^{+}$which has an acidic proton available at the C-2 position. This difference between $\mathrm{BMIm}^{+}$and $\mathrm{BMMIm}^{+}$ would explain why the latter registered a higher intensity for $\mathrm{E}_{\mathrm{p} 2}$ than the former. Moreover, the dianion formation was registered throughout the frequency range for $\mathrm{BMMImTf}_{2} \mathrm{~N}$ (IL with lowest viscosities) and only at low frequencies for $\mathrm{BMImBF}_{4}$ and $\mathrm{BMImTf}_{2} \mathrm{~N}$ (IL with highest viscosities). ${ }^{39-42}$ The dianion formation occurred from a nitro-anion radical reversible reduction, involving one more electron as also shown in Scheme 2.

In a complementary manner, information on the electrode process involving the NF reduction has been provided by studying the variation of $\mathrm{CV}$ scan rate, considering the range from 0.1 to $1.0 \mathrm{~V} \mathrm{~s}^{-1}$. Figure 6 shows the cyclic voltammograms of NF reduction registered in each IL, being only one reversible system registered. Following the same record obtained by using SWV, the voltammetric waves registered in all IL corresponding to the $\mathrm{R}-\mathrm{NO}_{2} / \mathrm{R}-\mathrm{NO}_{2}{ }^{-}$reversible couple, having the values of $\mathrm{E}_{\mathrm{pc}}-0.620 \mathrm{~V}\left(\mathrm{BMImBF}_{4}\right),-0.814 \mathrm{~V}\left(\mathrm{BMImTf}_{2} \mathrm{~N}\right)$ and $-0.970 \mathrm{~V}\left(\mathrm{BMMImTf}_{2} \mathrm{~N}\right)$. Probably, in function of the sensibility differences in comparison to the voltammetric pulse techniques the dianion formation was not observed by $\mathrm{CV}$. The relations between current cathodic values $\left(I_{p c}\right)$ and scan rate $(v)$ indicated that the process was predominantly controlled by diffusion. The linear relationships of $\mathrm{I}_{\mathrm{pc}} v s . \mathrm{n}^{1 / 2}$ (Figures $6 \mathrm{~b}$ ) showed this NF voltammetric behavior in all IL studied. Moreover, the slopes of the log-log plots (Figures 6c) close to 0.5 is an empiric indication of the diffusional controlled process, ${ }^{43}$ being the slope values: $0.51,0.53$ and 0.49 for $\mathrm{BMImBF}_{4}$,
BMImTf $_{2} \mathrm{~N}$ and BMMImTf ${ }_{2}$, respectively. It is worth mentioning that these results were obtained after the manual polishing of the working microelectrode among the measurements. These results complement and reinforce the NF voltammetric reduction behavior registered by using $\mathrm{SWV}$, in which the registers were carried out at lower scan rates $\left(<200 \mathrm{mV} \mathrm{s}^{-1}\right)$ while by using $\mathrm{CV}$ the scan rate range was wider and presenting higher values.

\section{Effect of the variation of NF concentration}

The knowledge on the electrochemical reduction of nitroheterocyclic compounds is consolidated in both, protic and aprotic media, normally having a conventional size electrode as working electrode. ${ }^{10-13,44-46}$ It can be observed that the cyclic voltammograms in Figure 6 show a similar profile to that recorded by a macroelectrode. Probably, the high viscosity and low conductivity of the IL promoted a certain hysteresis with microelectrode. That way, this behavior made it possible to acquire kinetic information related to the reaction order associated to the chemical step which may have occurred after the charge transfer in the NF electrochemical reduction. Applying the methodology of Olmstead-Nicholson, ${ }^{33}$ the current ratio $\left(\mathrm{I}_{\mathrm{pa}} / \mathrm{I}_{\mathrm{pc}}\right)$ is the main parameter as diagnostic criteria for the EC mechanism. The evaluation of the NF concentration effect on $\mathrm{I}_{\mathrm{pa}} / \mathrm{I}_{\mathrm{pc}}$ values can bring a kinetic response, because if the chemical reaction that occurs after the charge transfer process following firstorder kinetics, the current ratio values are kept constant with the concentration increase. ${ }^{11,13,44}$ On the contrary, as it can be seen in Figure 7, the $\mathrm{I}_{\mathrm{pa}} / \mathrm{I}_{\mathrm{pc}}$ values decrease as the NF concentration increases when its voltammetric reduction was performed in $\mathrm{BMImBF}_{4}$ and in $\mathrm{BMImT}_{\mathrm{f2}} \mathrm{N}$, indicating that the chemical reaction which occurs after the charge transfer process is second-order. ${ }^{11,33,44}$ Curiously, in $\mathrm{BMMImTf}_{2} \mathrm{~N}$ there was no radical formation record for $\mathrm{NF}$ concentrations higher than $10 \mathrm{mmol} \mathrm{L}^{-1}$. 
(A) $\mathrm{BMImBF}_{4}$
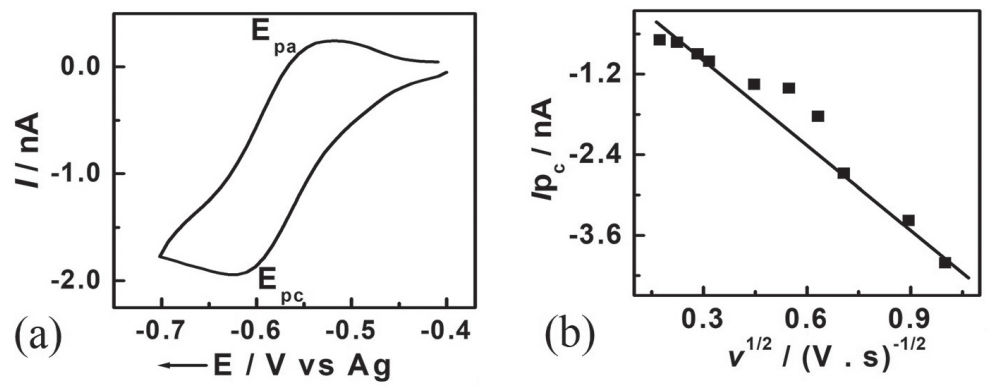

(B) $\mathrm{BMImTf}_{2} \mathrm{~N}$

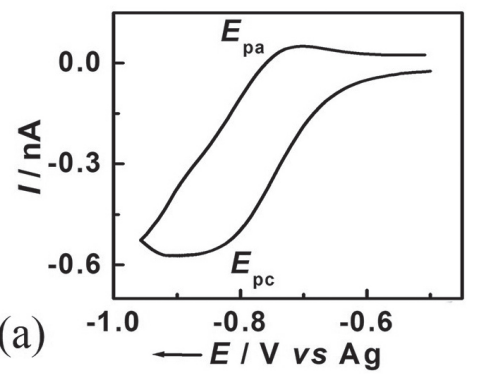

(b)

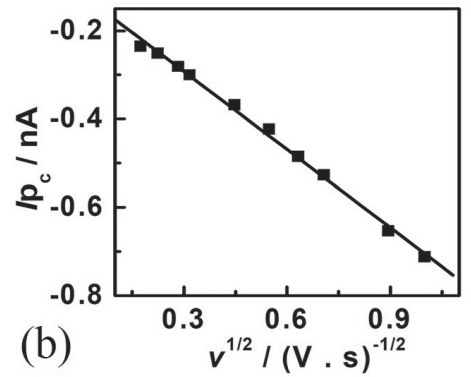

(C) $B M M I m T f_{2} N$

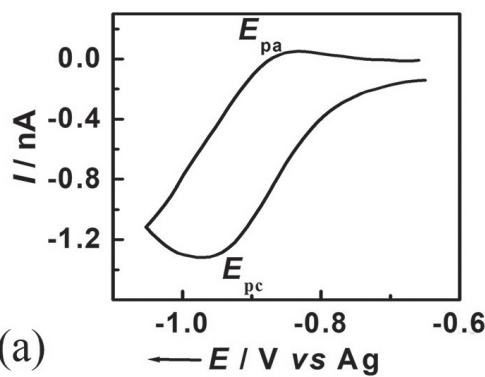

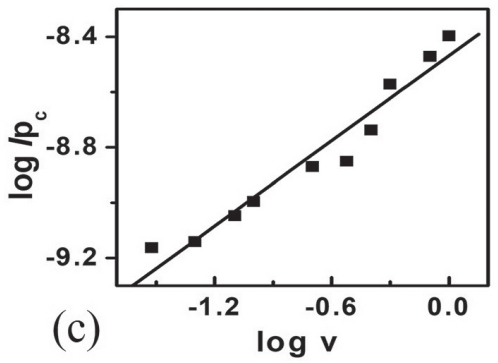

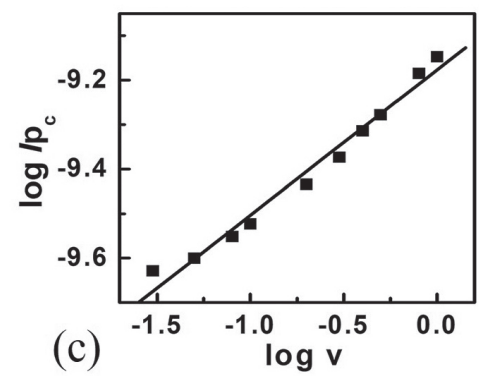

(c)

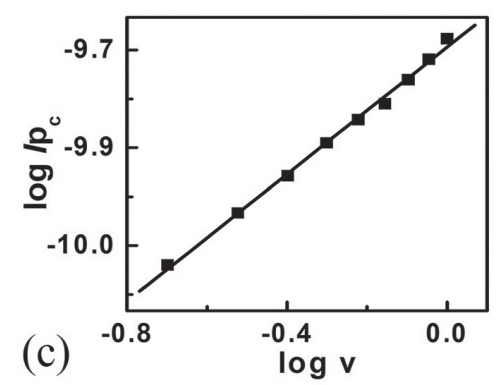

Figure 6. (a) Cyclic voltammograms of $\mathrm{NF} 10 \mathrm{mmol} \mathrm{L}^{-1}, v=500 \mathrm{mV} \mathrm{s}^{-1}$, (b) plots of $\mathrm{I}_{\mathrm{pc}} v s$. $v^{1 / 2}$ and (c) $\log \mathrm{I}_{\mathrm{pc}} v s . \log v$ in $\mathrm{BMImBF}_{4}(\mathrm{~A}) ; \mathrm{BMImTf}_{2} \mathrm{~N}(\mathrm{~B})$; $\mathrm{BMMImTf}_{2} \mathrm{~N}(\mathrm{C})$.

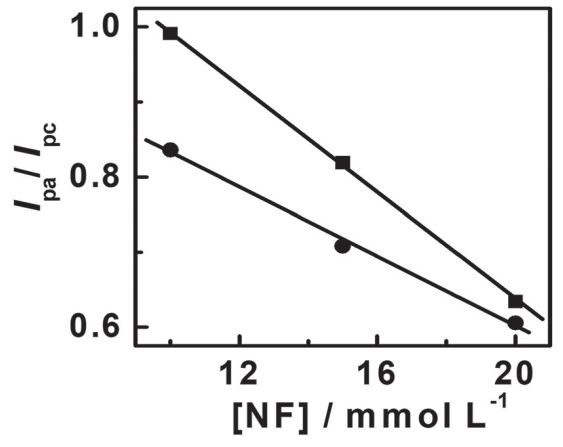

Figure 7. Variation of $\mathrm{I}_{\mathrm{pa}} / \mathrm{I}_{\mathrm{pc}}$ as a function of the NF concentration in $\mathrm{BMImBF}_{4}(\bullet)$ and in $\mathrm{BMImTf}_{2} \mathrm{~N}(\bullet), v=500 \mathrm{mV} \mathrm{s}^{-1}$. Initial potential $\operatorname{scan}\left(\mathrm{E}_{\mathrm{i}}\right)=0.4 \mathrm{~V}$ and final potential scan $\left(\mathrm{E}_{\mathrm{f}}\right)=-1.2 \mathrm{~V}$.

In a protic media, in which there are protons to donate to the radical, the disproportionation reaction is favored after the charge transfer process, because the protonation of the radical generates the intermediate $\mathrm{R}-\mathrm{NO}_{2} \mathrm{H} \bullet$, facilitating the fast reaction between the $\mathrm{R}-\mathrm{NO}_{2}{ }^{-}$and its neutral radical form, ${ }^{11,44,45}$ as shown by the reaction above:

$\mathrm{R}-\mathrm{NO}_{2} \mathrm{H}^{\cdot}+\mathrm{NO}_{2}{ }^{--}\left(+\mathrm{H}^{+}\right) \rightarrow \mathrm{R}-\mathrm{NO}_{2}+\mathrm{R}-\mathrm{NO}\left(+\mathrm{H}^{+}\right)$

On the other hand, as the IL used do not have ionizable hydrogen, the reactional model in aprotic media is better suited for the cases in which the mechanism proposed involves the nitrocompounds reduction in IL. Kang et al. ${ }^{26}$ suggest the azo-product electrogeneration from nitroanion radical generated on the electrode surface. Thus, the dimerization reaction could be considered, as well as a reaction between the radical formed at the electrode surface and the drug at the edge of the diffusion layer, being possible for the nitro-anion radical abstract a 
proton from another NF molecule following as a fatherson reaction. ${ }^{11,26,27}$ In any case, it can be reaffirmed that a second-order chemical reaction is the one that should occur.

Kinetic parameter calculations

According to the information obtained about the reaction order, the rate constants $\left(\mathrm{k}_{2}\right)$ were determined from the plots obtained between the kinetic parameters $\omega$ and $\tau$ for each IL studied (Figure 8). As there was no record of the anodic peak in lower concentrations, $10 \mathrm{mmol} \mathrm{L}^{-1}$ of NF have been chosen to work.

Considering the NF electrochemical reduction as an EC mechanism and complementing the results described above, a second-order chemical reaction was adopted, considering that the model for a dimerization reaction is the best fit to what occurred in the IL, similarly as already registered in aprotic media. ${ }^{11,33}$

For the NF in $\mathrm{BMImBF}_{4}$ and in $\mathrm{BMImTf}_{2} \mathrm{~N}$, the $\mathrm{k}_{2}$ values were calculated for the three different concentrations (10, 15 and $20 \mathrm{mmol} \mathrm{L}^{-1}$ ), reaching order values of $10^{2}$. These values were increased in function of the compound concentration increase (Table 1). By doubling the NF concentration, the $\mathrm{k}_{2}$ values reach a difference of up to a magnitude order. Similar behaviors were observed for NF in both IL, in which the highest stabilities were found for the

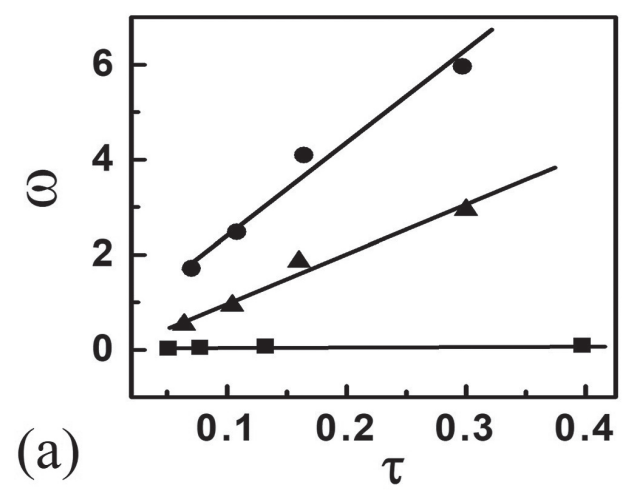

lowest concentrations and with the longest half-life times.

The NF kinetic constants were calculated in BMMImTf ${ }_{2} \mathrm{~N}$ in the same conditions mentioned above, although only one value was calculated for these IL having $10 \mathrm{mmol} \mathrm{L}^{-1}$ as NF concentration. The values on Table 1 were similar to those found in $\mathrm{BMImTf}_{2} \mathrm{~N}$ and $\mathrm{BMImBF}_{4}$. From the results for all IL, the radical stability was the highest in $\mathrm{BMImBF}_{4}$ with NF concentration of $10 \mathrm{mmol} \mathrm{L}^{-1}$, being the lowest $\mathrm{k}_{2}$ value and the highest $\mathrm{t}_{1 / 2}$ value in these conditions. This may be explained by the fact that the radical decay reaction occurred more slowly in $\mathrm{BMImBF}_{4}$, since it was the one presenting the highest viscosity followed by $\mathrm{BMImTf}_{2} \mathrm{~N}$ and $\mathrm{BMMImTf}_{2} \mathrm{~N}$. In addition, as already mentioned, the composition of cations and anions of IL also influences the radical stability. In this sense, larger stability was observed in liquids containing the $\mathrm{BMIm}^{+}$cation, which can be explained by a stronger interaction in function of a lower distance between the radical anion charge center and the cation. This occurred due to the planar geometry of the imidazolium BMIm ${ }^{+}$ ring and by the imidazolium cation ability for hydrogenbonding. ${ }^{34}$ For $\mathrm{BMMIm}^{+}$cation, the values calculated for the $\mathrm{k}_{2}$ and $\mathrm{t}_{1 / 2}$ showed smaller radical stability, inferring that due the bulky cation, a large steric hindrance occurred around the $\mathrm{R}-\mathrm{NO}_{2}$ group, which decreased the ion-pair interaction..$^{23,34}$ Regarding the anions $\mathrm{BF}_{4}^{-}$and $\mathrm{Tf}_{2} \mathrm{~N}^{-}$, this

(b)

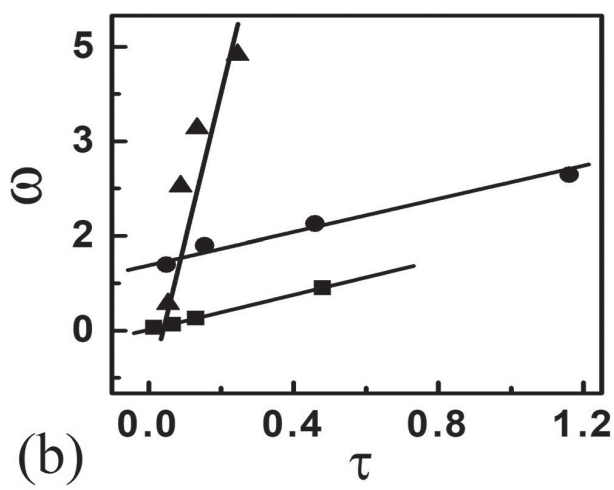

(c)

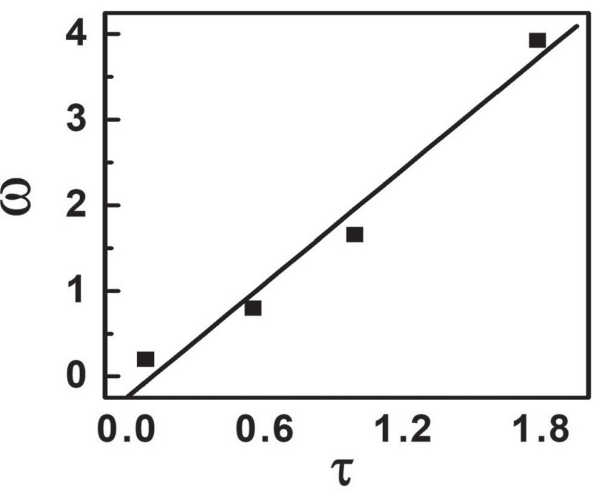

Figure 8. The kinetic parameters $\omega$ as a function of $\tau$ for $\mathrm{NF} 10.0(\boldsymbol{\bullet}), 15.0(\bullet)$ and $20.0 \mathrm{mmol} \mathrm{L}^{-1}(\boldsymbol{\Delta})$ for BMImBF$_{4}(\mathrm{a}), \mathrm{BMImTf}_{2} \mathrm{~N}(\mathrm{~b})$ and $\mathrm{BMMImTf}_{2} \mathrm{~N}(\mathrm{c})$. 
Table 1. $\mathrm{k}_{2}$ and $\mathrm{t}_{1 / 2}$ values for the second-order chemical reaction from nitro-anion radical in IL

\begin{tabular}{|c|c|c|c|c|c|c|}
\hline \multirow{3}{*}{ IL } & \multicolumn{6}{|c|}{$\mathrm{NF}$ concentration / $\left(\mathrm{mmol} \mathrm{L}^{-1}\right)$} \\
\hline & \multicolumn{2}{|l|}{10} & \multicolumn{2}{|l|}{15} & \multicolumn{2}{|l|}{20} \\
\hline & $\mathrm{k}_{2} \times 10^{-2} /\left(\mathrm{mol} \mathrm{L}^{-1} \mathrm{~s}^{-1}\right)$ & $\mathrm{t}_{1 / 2} / \mathrm{s}$ & $\mathrm{k}_{2} \times 10^{-2} /\left(\mathrm{mol} \mathrm{L}^{-1} \mathrm{~s}^{-1}\right)$ & $\mathrm{t}_{1 / 2} / \mathrm{s}$ & $\mathrm{k}_{2} \times 10^{-2} /\left(\mathrm{mol} \mathrm{L}^{-1} \mathrm{~s}^{-1}\right)$ & $\mathrm{t}_{1 / 2} / \mathrm{s}$ \\
\hline $\mathrm{BMImBF}_{4}$ & 0.533 & 1.87 & 1.25 & 0.54 & 5.02 & 0.10 \\
\hline $\mathrm{BMImTf}_{2} \mathrm{~N}$ & 1.36 & 0.73 & 8.41 & 0.08 & 16.8 & 0.03 \\
\hline $\mathrm{BMMImTf}_{2} \mathrm{~N}$ & 2.22 & 0.45 & - & - & - & - \\
\hline
\end{tabular}

NF: nitrofurazone; IL: ionic liquids; $\mathrm{k}_{2}$ : rate constant value for the second-order reaction for the nitro-anion radical decay; $\mathrm{t}_{1 / 2}$ : half-life.

interaction is also affected by the anion size, being stronger when it comes to a small anion, as in the case of the $\mathrm{BF}_{4}^{-}$, since its substitution by the radical anion is easier than when a larger anion as $\mathrm{Tf}_{2} \mathrm{~N}^{-}$is used..$^{46}$ In this case, combining the $\mathrm{BMIm}^{+}$cation with the $\mathrm{BF}_{4}^{-}$anion, the best stability conditions for the radical formation in terms of viscosity and pairing interactions was obtained.

\section{Conclusions}

The NF voltammetric reduction in the three ionic liquids showed that the nitro-anion radical formation was recorded in all cases, followed by the formation of its respective dianion, being two processes characterized as reversible. Based on the SWV parameters variations, the reagent and product adsorption processes on electrode surface was demonstrated only for lower frequency values, being predominantly controlled by diffusion for the frequency range used. The number of electrons estimate showed that one electron is involved in each reduction step, confirming the radical and the dianion formations. The CV study showed the existence of an EC mechanism, in which a chemical reaction occurred after the charge transfer process corresponding to the nitro-anion radical generation, being a second-order chemical reaction. The kinetic constant values were calculated, having their values increased as function of the NF concentration increase. Consequently, the radical half-life time values indicate the largest stability in $\mathrm{BMImBF}_{4}$. The introduction of IL as a reaction medium, using the microelectrode as a working electrode, proved to be a good alternative for kinetic and mechanistic studies of nitroheterocyclic compounds.

\section{Supplementary Information}

Supplementary information about characterization by ${ }^{1} \mathrm{H}$ NMR, elemental analysis and physicochemical parameters of the ionic liquids and the number of electrons involved in the NF voltammetric reduction are available free of charge at http://jbcs.sbq.org.br as PDF file.

\section{Acknowledgments}

The scholarship for L. D. Chiavassa by the Coordenação de Aperfeiçoamento de Pessoal de Nível Superior (CAPES) and the financial support from FAPESP (2018/20826-4) for Fernanda F. Camilo are aknowledged.

\section{References}

1. Ju, K.-S.; Parales, R. E.; Microbiol. Mol. Biol. Rev. 2010, 74, 250.

2. Haderlein, S. B.; Weissmahr, K. W.; Schwarzenbach, R. P.; Environ. Sci. Technol. 1996, 30, 612.

3. Raether, W.; Hänel, H.; Parasitol. Res. 2003, 90, S19.

4. Chung, M. C.; Bosquesi, P. L.; Santos, J. L.; Curr. Pharm. Des. 2011, 17, 3515 .

5. Bot, C.; Hall, B. S.; Álvarez, G.; di Maio, R.; González, M.; Cerecetto, H.; Wilkinson, S. R.; Antimicrob. Agents Chemother. 2013, 57, 1638.

6. Giarolla, J.; Ferreira, E.; Mini-Rev. Med. Chem. 2015, 15, 219.

7. Sales, P. A. J.; Molina, I.; Murta, S. M. F.; Montalvá, A. S.; Salvador, F.; Oliveira, R. C.; Carneiro, C. M.; Am. J. Trop. Med. Hyg. 2017, 97, 1289.

8. Coura, J. R.; Pereira, J. B.; Rev. Soc. Bras. Med. Trop. 2012, $45,286$.

9. Tocher, J. H.; Gen. Pharmacol. 1997, 28, 485.

10. Viodé, C.; Bettache, N.; Cenas, N.; Siegel, R. L. K.; Chauvière, G.; Bakalara, N.; Périé, J.; Biochem. Pharmacol. 1999, 57, 549.

11. Squella, J.; Bollo, S.; Nunez-Vergara, L.; Curr. Org. Chem. $\mathbf{2 0 0 5}, 9,565$.

12. La-Scalea, M. A.; Menezes, C. M. S.; Julião, M. S. S.; Chung, M. C.; Serrano, S. H. P.; Ferreira, E. I.; J. Braz. Chem. Soc. 2005, 16, 774.

13. Brito, C. L.; Trossini, G. H. G.; Ferreira, E. I.; La-Scalea, M. A.; J. Braz. Chem. Soc. 2013, 24, 1964.

14. Chiavassa, L. D.; La-Scalea, M. A.; J. Solid State Electrochem. 2018, 22, 1395.

15. Almeida, M. O.; Maltarollo, V. G.; Toledo, R. A.; Shim, H.; Santos, M. C.; Honorio, K. M.; Curr. Med. Chem. 2014, 21, 2266. 
16. Zuman, P.; J. Solid State Electrochem. 2011, 15, 1753.

17. Sinha, A.; Dhanjai; Jain, R.; Zhao, H.; Karolia, P.; Jadon, N.; Microchim. Acta 2018, 185, 89.

18. Dumitrescu, E.; Andreescu, S. In Methods in Enzymology, vol. 589, $1^{\text {st }}$ ed.; Thompson, R. B.; Fierke, C., eds.; Elsevier: London, UK, 2017.

19. Dhanjai; Sinha, A.; Lu, X.; Wu, L.; Tan, D.; Li, Y.; Chen, J.; Jain, R.; TrAC, Trends Anal. Chem. 2018, 98, 174.

20. Tanner, E. E. L.; Barnes, E. O.; Goodrich, P.; Hardacre, C.; Compton, R. G.; J. Phys. Chem. C 2015, 119, 3634.

21. Silvester, D. S.; Compton, R. G.; Z. Phys. Chem. 2006, 220, 1247.

22. Hubbard, C. D.; Illner, P.; Eldik, R. V.; Chem. Soc. Rev. 2011, 40, 272.

23. Zhang, Y.; Mao, X.; Ren, S.; Ma, C.; Chem. Res. Chin. Univ. 2014, 30, 293.

24. Yao, N.; Wang, H. B.; Hu, Y. L.; Mini-Rev. Org. Chem. 2017, 14, 237.

25. Silvester, D. S.; Analyst 2011, 136, 4871.

26. Kang, C.; Lee, J.; Silvester, D. S.; J. Phys. Chem. C 2016, 120, 10997.

27. Lee, J.; Hay, C. E.; Silvester, D. S.; Aust. J. Chem. 2018, 71, 818.

28. Xiao, C.; Rehman, A.; Zeng, X.; Anal. Chem. 2012, 84, 1416.

29. Inzelt, G. In Handbook of Reference Electrodes; Inzelt, G.; Lewenstam, A.; Scholz, F., eds.; Springer: Berlin, Heidelberg, Germany, 2013.

30. Baur, J. E.; Wightman, R. M.; J. Electroanal. Chem. Interfacial Electrochem. 1991, 305, 73.

31. Roffel, B.; van de Graaf, J. J.; J. Chem. Eng. Data 1977, 22, 300 .
32. Bazito, F. F. C.; Kawano, Y.; Torresi, R. M.; Electrochim. Acta 2007, 52, 6427.

33. Olmstead, M. L.; Hamilton, R. G.; Nicholson, R. S.; Anal. Chem. 1969, 41, 260.

34. Lagrost, C.; Preda, L.; Volanschi, E.; Hapiot, P.; J. Electroanal. Chem. 2005, 585, 1.

35. Souza, D.; Machado, S. A. S.; Avaca, L. A.; Quim. Nova 2003, 26,81 .

36. Mirceski, V.; Komorsky-Lovric, S.; Lovric, M.; Square-Wave Voltammetry: Theory and Application; Scholz, F., ed.; Springer: Berlin, Heidelberg, Germany, 2007.

37. Lovrić, M.; Jadreško, D.; Komorsky-Lovrić, Š.; Electrochim. Acta 2013, 90, 226.

38. Silvester, D. S.; Wain, A. J.; Aldous, L.; Hardacre, C.; Compton, R. G.; J. Electroanal. Chem. 2006, 596, 131.

39. Ohno, H.; Electrochemical Aspects of Ionic Liquids, $2^{\text {nd }}$ ed.; Wiley-Interscience: New Jersey, USA, 2011.

40. Yuan, W.-L.; Yang, X.; He, L.; Xue, Y.; Qin, S.; Tao, G.-H.; Front. Chem. 2018, 6, 59.

41. Dupont, J.; J. Braz. Chem. Soc. 2004, 15, 341.

42. Aranowski, R.; Cichowska-Kopczyńska, I.; Dębski, B.; Jasiński, P.; J. Mol. Liq. 2016, 221, 541.

43. Gosser Jr., D. K.; Cyclic Voltammetry: Simulation and Analysis of Reaction Mechanisms; VCH: New York, 1993.

44. Brito, C. L.; Ferreira, E. I.; La-Scalea, M. A.; J. Solid State Electrochem. 2020, 24, 1969.

45. Mandal, P. C.; J. Electroanal. Chem. 2004, 570, 55.

46. Cruz, H.; Gallardo, I.; Guirado, G.; Green Chem. 2011, 13, 2531. 